\title{
Aktivitas Riset CNN Indonesia dalam Penyelenggaraan Special Event Meet Up "Positive Generation"
}

\author{
Ayu Puspa Yurita1, Hanny Hafiar², dan Heru Ryanto Budiana ${ }^{3}$ \\ ${ }^{1}$ Internship Development Program CNN Indonesia, Jakarta \\ ${ }^{2,3}$ Program Studi Hubungan Masyarakat, Fakultas Ilmu Komunikasi, \\ Universitas Padjadjaran, Bandung
}

\begin{abstract}
ABSTRAK
Penelitian ini bertujuan untuk mengetahui pelaksanaan riset dalam kegiatan special event yang dilakukan oleh CNN Indonesia dalam menyelenggarakan Meet Up "Positive Generation" untuk menghasilkan revenue perusahaan, serta untuk meningkatkan kesadaran generasi milenials terhadap CNN Indonesia. Penelitian ini menggunakan tahapan riset pada Event Management Process Joe Goldblatt sebagai landasan konsep. Penelitian ini adalah penelitian kualitatif dengan pendekatan studi deskriptif. Teknik pengumpulan data yang dilakukan dengan wawancara mendalam, observasi partisipan pasif, dan studi kepustakaan, dengan teknik pengumpulan key informan purposive sampling. Teknik analisis data menggunakan tiga tahap yaitu reduksi data, penyajian data, serta penarikan kesimpulan.Hasil penelitian ini mengemukakan bahwa proses riset yang dilakukan CNN Indonesia diperoleh berdasarkan data lapangan yang didapat melalui observasi langsung saat event berlangsung, maupun wawancara mendalam dengan pihak-pihak yang terlibat langsung dalam proses riset event Meet Up "Positive Generation" yang diselenggarakan oleh CNN Indonesia. Sebagai penyelenggara Meet Up "Positive Generation", CNN Indonesia melakukan riset terlebih dahulu untuk mengetahui kebutuhan dan keinginan target sasaran. Bentuk riset yang dilakukan penyelanggara Meet Up "Positive Generation" adalah menentukan pembicara-pembicara yang akan mengisi event Meet Up "Positive Generation" berdasarkan online riset melalui akun Instagram ataupun You Tube. Selain itu juga menentukan kampus-kampus mana saja yang dapat dijadikan tempat pelaksanaan untuk diadakannya event Meet Up "Positive Generation".
\end{abstract}

Kata-kata Kunci: Special event; proses riset; generasi milenials; CNN Indonesia; meet up

\section{CNN Indonesia's Research Activities in the Organizing of Special Event Meet Up "Positive Generation"}

\begin{abstract}
This study aims to determine the research process by CNN Indonesia in Meet Up "Positive Generation" togenerate revenue for the company, and also to raise awareness millennials generation. This study uses Joe Goldblatt's Event Management Process as the cornerstone concept. This study used a qualitative research approach descriptive study. Data was collected by in-depth interviews, passive participant observation, and literature study. The key informant collection technique used is purporsive sampling. Data were analyzed using three stages, which is data reduction, data display, and conclusion drawing. The results of this study suggest that the research process conducted by CNN Indonesia was based on field data obtained through direct observation during the event, as well as in-depth interviews with parties directly involved in the event research process Meet Up "Positive Generation" held by CNN Indonesia. As the organizer of the Meet Up "Positive Generation", CNN Indonesia conducted research first to find out the needs and desires of the target audience. The form of research conducted by the organizer of the Meet Up "Positive Generation" is to determine the speakers who will fill the Meet Up "Positive Generation" event based on online research through an Instagram account or You Tube. In addition, it also determines which campuses can be used as the venue for holding the event Meet Up "Positive Generation".
\end{abstract}

Keywords: Special event; the research process; millennials generation; CNN Indonesia; meet up

Korespondensi:Ayu Puspa Yurita. CNN Indonesia. Jl. Kapten Tendean Kav 12-14 A, Mampang Prapatan, Jakarta12790.Email: ayupuspayurita97@gmail.com 


\section{PENDAHULUAN}

Cable News Network Indonesia atau juga dikenal dengan $\mathrm{CNN}$ Indonesia merupakan saluran berita yang dimiliki oleh Trans Media yang bekerja sama dengan Turner Internasional, perusahaan pemilik CNN. CNN Indonesia disiarkan pertama kali pada 17 Agustus 2015, dan melakukan peluncuran utamanya yang berlangsung sejak 15 Desember 2015 dalam rangka memperingati ulang tahun Trans Media yang ke 14. Sama seperti CNN/U.S. dan CNN Internasional, menyajikan berita dengan fokus pada berita umum, bisnis, olahraga, teknologi dan hiburan dengan memuat konten lokal dan internasional hanya saja menggunakan bahasa Indonesia sebagai bahasa pengantarnya.

CNN Indonesia merupakan platform pemberitaan kelas dunia yang kredibel dengan mengutamakan independensi, akurasi, transparansi, dan fairness. CNN Indonesia memiliki lebih dari 20 program dengan news value yang berbeda-beda juga para news achors yang sangat handal dalam menyampaikan berita kepada masyarakat. Menurut Bapak Fred selaku Head of Marketing Public Relations Departement CNN Indonesia menyatakan bahwa:

"Untuk mendapatkan sebuah awareness CNN Indonesia mendapatkannya dengan melakukan 2 fungsi dan tujuan PR CNN Indonesia yaitu partnership specialist dan event specialist. Selain program-progam on air yang sudah menjadi poin utama tv berita, cara lain untuk mendapatkan bahkan meningkatkan awareness masyarakat terhadap $\mathrm{CNN}$ Indonesia juga dengan membuat program-progam off air, yaitu melalui event Meet $U p$ dengan tema positive generation," (Jebada, 2019).

Meet Up merupakan acara seminar kreatif yang didalamnya juga terdapat kompetisi yang diselenggarakan oleh CNN Indonesia. Awalnya event ini diinisiasi oleh salah satu staff of marketing public relations Mas Dicky Ferdiansyah, yang pada saat itu melihat bahwa CNN Indonesia perusahaan yang bagus namun belum memiliki activity. Akhirnya atas inisiasi ide kreatif tersebut, CNN Indonesia membuat event off air dengan nama CNN Indonesia Meet Up "Positive Generation". CNN Indonesia Meet Up pertama kali diselenggarakan pada $18 \mathrm{Mei}$ 2016. Awalnya event Meet Up itu mengambil dari program on air yang ada di CNN Indonesia yang dibuat event off air, dengan tujuannya untuk mempromosikan program-program yang ada di CNN Indonesia. Namun tujuan itu hanya sekedar untuk promosikan program yang ada, tanpa memikirkan tujuan jangka panjangnya. Akhirnya CNN Indonesia mengubah konsep dari sebelumnya, dengan melakukan kolaborasi dengan kampus- kampus yang ada di Indonesia dengan memiliki tujuan yang pasti.

Setiap tahunnya event Meet $U p$ memiliki tema yang berbeda-beda dengan memiliki value yang berbeda-beda setiap tahunnya. Kali ini event Meet Up bertemakan "Positive 
Generation" dengan memiliki objective event yaitu untuk memberikan edukasi mahasiswa terkait materi yang sedang menarik dikalangan remaja, agar mereka sudah bisa menentukan akan melakukan apa untuk menjadi generasi yang berkualitas untuk bangsa, memberikan pengaruh positif kepada remaja serta menjauhkan mereka dari hal hal yang kurang baik seperti pernikahan dini, free sex, dan napza, serta memberikan pengalaman baru bagi mahasiswa terkait ilmu jurnalistik, new media, dan entrepreneurship. Hal yang membedakan antara Meet Up "Positive Generation" dengan event-event sejenis adalah dimana event Meet Up "Positive Generation" bisa live secara langsung ke tv acaranya. Sedangkan acaraacara lainnya, hanya terekspos di acara lokasi saja.

"Keunikannya dari event Meet Up"Positive Generation" ini dimana kita bisa live secara langsung ke tv acaranya. Kalau acara-acara lainnya, cuma terekspos di acara lokasi doang. Tapi event Meet Up "Positive Generation" yang kita adakan itu selalu ada live report, jadi langsung ke tv," (Ferdiansyah, 2019).

Selain itu event Meet $U p$ "Positive Generation" memiliki tujuan yang jelas yakni untuk meningkatkan awareness dan meningkatkan pengetahuan masyarakat khususnya generasi muda di Indonesia terhadap CNN Indonesia melalui promosi pada event Meet Up "Positive Generation" juga mempersiapkan konsumen CNN Indonesia di masa depan. Bahwa di masa depan itu, orang yang mengonsumsi $\mathrm{CNN}$ Indonesia tidak hanya dari layar tv, melainkan bisa melalui YouTube, Instagram, atau dari manapun. Selain awareness yang ingin dicapai selain itu juga ada tujuan KPI (Key Performance Indicator) yang ingin dicapai. Departemen Marketing Public Relations CNN Indonesia dituntut untuk dapat menghasilkan revenue dari setiap event yang diadakan.

"Program Meet Up "Positive Generation" ini sebagai upaya bagaimana caranya kita menyiapkan konsumen CNN Indonesia di masa depan. Bahwa di masa depan itu, orang yang mengonsumsi $\mathrm{CNN}$ Indonesia tidak hanya dari layar televisi saja, melainkan bisa melalui YouTube, Instagram, atau dari manapun. Tapi sekali lagi, CNN Indonesia menonjolkan nilai kredibel dan bisa dipercaya. Jadi itu adalah ajang CNN Indonesia melakukan promosi di event Meet Up," (Jebada, 2019).

Hal ini kemudian ditambahkan langsung oleh Project Manager Meet $U p$ "Positive Generation" bahwa setiap event off air yang diadakan oleh CNN Indonesia harus dapat menghasilkan revenue pada perusahaan.

"Nah setelah itu, kan bedakan dituntut sama kantor untuk menghasilkan revenue. Itu dimulai setelah meet up yang di UNJ. Setelah di UNJ, ada pengumuman dari kantor, dituntut untuk menghasilkan revenue dari event," (Ferdiansyah, 2019).

Untuk menghasilkan revenue pada setiap event yang diadakan $\mathrm{CNN}$ Indonesia tentu membutuhkan pihak eksternal dalam 
menjalankan event tersebut. Dalam event Meet Up "Positive Generation", CNN Indonesia mencari sponsor yang memiliki visi yang sama dalam merealisasikan event tersebut. Event Meet Up "Positive Generation" juga berkolaborasi dengan BkkbN dalam mengkampanyekan campaign yang dimiliki BkkbN yaitu GenRe. Di sisi lain BkkbN GenRe memiliki misi mencetak generasi pemimpin bangsa masa depan dengan kompetitif ditengah perkembangan teknologi yang kian pesat. Kolaborasi CNN Indonesia dengan BkkbN GenRe diharapkan mampu menginspirasi para mahasiswa atau generasi muda melalui rangkaian kegiatan yang berkualitas, menarik, dan relevan dengan kebutuhan mereka.

Jadi dapat disimpulkan tujuan diadakannya event $\mathrm{CNN}$ Indonesia Meet $U p$ "Positive Generation" adalah untuk mengedukasi mahasiswa terkait materi yang sedang menarik dikalangan remaja, agar mereka dapat menentukan akan melakukan apa untuk menjadi generasi yang berkualitas untuk bangsa, dapat memberikan pengaruh positif kepada remaja serta menjauhkan mereka dari hal yang kurang baik seperti pernikahan dini, free sex, dan napza, kemudian dapat memberikan pengalaman baru bagi mahasiswa terkait ilmu jurnalistik, new media, dan entrepreunership.

Menurut Yaverbaum, mengemukakan special event adalah media publisitas yang efektif karena dapat membantu dalam memasarkan perusahaan dan produk jasa kepada publik, sangat bersifat promosi, serta mampu mendapatkan publisitas banyak dari pihak media massa (Pudjiastuti, 2010).

"Special event are effective vehicles publicity because they help market your company, product or service to the public, and they promotable and can get you a lot of press coverage."

Konten acara yang akan berlangsung di Meet Up "Positive Generation" ada dua, yaitu seminar "Genre" Positif, dimana seminar akan menyuguhkan banyak konten positif yang bisa jadi inspirasi bagi remaja untuk menjadi cerdas dan berkualitas di masa depan nanti, dimana konten seminarnya terdapat 3 sesi yaitu Journalist Session, New Media Session, dan Entrepreuner Session. Journalist Session dimana dilakukan sharing pengalaman mereka menjadi jurnalis dan akan coaching clinic bagaimana caranya $\mathrm{CNN}$ Indonesia Live Report. Kemudian new media session untuk memberikan motivasi kepada anak-anak kampus agar dapat memaksimalkan penggunaan media yang digunakan dengan bijak dan benar. Konten seminar yang ketiga adalah entrepreuner session dimana konten tersebut guna memotivasi anakanak kampus agar bisa menjadi pengusaha muda yang kreatif. Selain ketiga sesi tersebut, ada sesi khusus mengenai campaign GenRe 
yang dijelaskan langsung oleh pihak BkkbN.

Konten acara yang kedua adalah Vlog "GenRe" Competition, dimana kompetisi membuat vlog degan tema "Say no to nikah dini, free sex dan napza". Vlog akan di upload ke sosial media masing-masing perserta untuk menambah eksposure dari Genre. Selain itu, event Meet Up "Positive Generation" ini dipimpin oleh moderator yang diambil langsung dari news anchor $\mathrm{CNN}$ Indonesia dan juga terhadap konten hiburan yaitu terdapat music performance, yang dihadiri oleh musisi terkenal Indonesia.

Persiapan penyelenggaraan CNN Indonesia Meet Up "Positive Generation" terbilang sangat singkat atau hanya memerlukan waktu yang tidak lama. Berdasarkan hasil pra survei, semenjak perusahaan menuntut revenue pada setiap event yang diadakan oleh CNN Indonesia. Departemen Marketing Public Relations harus bisa membuat konten yang lebih menarik dari sebelumnya agar dapat mencapai tujuan yang sudah ditentukan, namun juga dapat menghasilkan revenue bagi perusahaan. Hal yang pertama kali dilakukan CNN Indonesia tentu mencari pihak sponsor yang bisa diajak kerjasama untuk berkolaborasi. Setelah itu, project manager event Meet Up "Positive Generation" membuat konsep yang nantinya akan dipresentasikan pada klien yaitu BkkbN. Dalam hal ini, CNN Indonesia harus memasukkan konten campaign GenRe pada setiap event Meet Up "Positive Generation". "Konsep awal itu dari aku, aku selaku project manager event Meet up ini. Nah aku yang buat konsepnya kemudian aku lempar ke om Fred dulu. Dari om Fred di review semuanya takut ada typo atau apa gitu dan kalau sudah selesai baru dilempar ke klien. Nah dari klien ini biasanya ada revisi-revisi, misal aku maunya event-nya kayak gini kayak gini, narsumnya kayak gini, bintang tamunya ini. Nah apa yang diinginkan klien itu langsung ditranskrip lagi sama aku dengan proposal yang baru dengan proposal yang sudah direvisi. Setelah oke, barulah kita jalan," (Ferdiansyah, 2019).

Setelah konsep kolaborasi sudah mendapat persetujuan dari pihak klien maupun atasanya, yang dilakukan selanjutnya adalah menentukan kampus-kampus yang akan dijadikan parner untuk dilaksanakan event Meet $U p$ ini, kemudian menghubungi narasumber-narasumber yang sudah ditentukan diawal. Proses penentuan kampus-kampus mana saja yang akan dijadikan parner hingga menghubungi narasumber mana yang pasti akan dijadikan pengisi acara pada event Meet Up ini tidak membutuhkan waktu yang lama, karena waktu deadline yang sudah disepakati diawal.

"Yang pertama itu riset tempatnya, kampus grade nya harus $\mathrm{A}$ atau $\mathrm{B}$, yang penting kampusnya harus baguslah. Nah dari situ kan kita meeting sama anak kampusnya, sama dekan-dekannya, dari situ kita menentukan penontonnya bakal siapa aja, program jurusannya harus apa aja. Sebenarnya risetnya lebih ke sharing dengan mereka sih, sharing dengan orang kampusnya langsung, seperti apa event itu. Jadi yang pertama cari dulu tempatnya, terus kita datengin ke tempatnya baru kita sharing siapa yang nanti bakal jadi panitianya, tujuan acaranya kemana. Gak 
lama sih risetnya, cuma sekali ketemua aja gitu," (Ferdiansyah, 2019).

Setelah mempersiapkan konsep acara, akhirnya terbentuklah empat sesi acara yang akan berlangsung di Meet Up "Positive Generation" yaitu Journalist Session, New Media Session, Entrepreuner Session dan BkkbN Session. Selanjutnya penyelenggara mempersiapkan waktu dan tempat, penyelenggara membuat desain publikasi seperti e-poster, spanduk, photo booth dan umbul-umbul untuk mendukung keberlangsungan event tersebut. Desain yang dibuat berdasarkan mengikuti trend kekinian dengan menggunakan warna yang eye catching.

Untuk mendukung kesuksesan acara, CNN Indonesia membentuk kepanitian eksternal dari pihak kampus yang terlibat. Kepanitian eksternal yang dibutuhkan untuk membantu event secara teknis seperti, seksi konsumsi, logistik, registrasi, dan juga runner. Panitia berkomunikasi satu sama lain dengan menggunakan media sosial Whats up untuk saling bertukar informasi mengenai perkembangan persiapan acara. Panitia penyelenggara melakukan evaluasi setelah event Meet Up "Positive Generation"berlangsung. Evaluasi yang dilakukan seperti kumpul untuk melakukan sharing-sharing dengan pihak klien BkkbN. Penyelenggara mengukur keberhasilan acara melihat dari berhasil mendapatkan revenue untuk perusahaan.

"Nah evaluasi kalau setelah selesai event, itu emang ada suka kumpul. Ngebahas apa aja yang sebenarnya kurang, emang yang salah kita lakuin. Nah itu sebenarnya bisa jadi pelajaran untuk kita dan juga untuk pihak kampusnya untuk menyelenggarakan event selanjutnya. Udah belajar dari event yang kita lakukan tadi, kitapun belajar dari evaluasi untuk event selanjutnya seperti apa. Sebenarnya kayak sharing-sharing biasa aja sih," (Ferdiansyah, 2019).

Namun berdasarkan hasil wawancara pra survei yang dilakukan peneliti kepada panitia eksternal dari kampus tempat diselenggarakannya event Meet Up "Positive Generation", dimana terdapat kekurangan pada event tersebut. Hal ini dinyatakan oleh Farah, sebagai koordinator panitia eksternal kampus $\mathrm{UNJ}$ :

\section{"Event Meet Up "Positive Generation"} yang diadain sama CNN Indonesia ini udah bagus sih, kerjasama sama BkkbN dalam mensosialisasikan campaign-nya GenRe itu juga udah bagus. Cuma paling kalau dari saya kurangnya dari kontennya sih. Kan sebelumnya CNN Indonesia juga pernah ngadain event Meet Up yang pertama kali di UNJ, cuma saya melihat tidak ada perbedaan konten dari event yang sebelumnya. Paling cuma ditambah konten dari BkkbN nya aja, tetapi selebihnya sama aja gitu," (Farah, 2019).

Hal ini juga diperkuat dengan pernyataan dari Aliya Alatas yang merupakan salah satu peserta event Meet Up "Positive Generation" di Universitas Indonesia:

"Awalnya saya tertarik banget dengan 
adanya event Meet Up "Positive Generation" yang diadain CNN Indonesia ini. Saya dan teman-teman saya tahu tentang event ini dari dosen saya sebagai kuliah umum. Jadi angkatan saya diwajibkan untuk hadir pada event tersebut. Tapi saya tidak melihat adanya publikasi langsung dari pihak CNN Indonesia nya. Terus menurut saya dan teman-teman saya acaranya kurang menarik sih, materinya bikin ngantuk gitu, banyak anak-anak yang kayak tidur dibawah gitu atau cabut gitu. Terus ini sih, aku kan dateng telat ya pas hari $\mathrm{H}$, tapi itu karena ada perubahan jadwal gitu kak, awalnya dikasih tau jam berapa tapi tiba-tiba dimajuin gitu. Jadi banyak yang dateng telat, terus pas nanya ke panitianya, tapi kayak ngejawabnya lama gitu, jadinya kita nunggu lama gitu diluar," (Alatas, 2019).

Hal ini membuktikan bahwa terdapat ketidaksesuaian antara tujuan yang ingin dicapai perusahaan dengan realitanya, melihat dari ketiga tujuan yang ingin dicapai, hanya satu dari tiga tujuan yang sudah tercapai yaitu revenue. Sedangkan berdasarkan hasil pra survei peneliti, tujuan untuk meningkatkan pemahaman terhadap $\mathrm{CNN}$ Indonesia khususnya mengenai new media dan jurnalistik serta untuk mengedukasi generasi muda atau generasi milenial terkait materi yang sedang menarik dikalangan remaja, agar mereka dapat menentukan akan melakukan apa untuk menjadi generasi yang berkualitas untuk bangsa yang ingin dicapai oleh CNN Indonesia belum tercapai sampai pasca event Meet Up "Positive Generation" ini diadakan. Hal ini dikarenakan proses manajemen special event yang dilakukan oleh CNN Indonesia belum maksimal melihat data pra survei yang didapat peneliti.

Berdasarkan uraian diatas, peneliti tertarik untuk melakukan penelitian lebih dalam mengenai bagaimana manajemen special event Meet Up "Positive Generation" oleh CNN Indonesia. Peneliti merasa bahwa penelitian harus dilakukan, mengingat bahwa special event merupakan salah satu tools dalam public relations. Dengan meneliti manajemen special event peneliti dapat berkontribusi dalam konteks keilmuan komunikasi dan dapat diaplikasikan oleh CNN Indonesia dalam penyelenggaraan acara selanjutnya. Penelitian ini dilakukan guna mengetahui proses riset yang dilakukan $\mathrm{CNN}$ Indonesia dalam membuat special event Meet Up "Positive Generation".

\section{TINJAUAN PUSTAKA}

(Goldblatt, 2013) mendefinisikan special event sebagai "unique moment in time celebrated with ceremony and ritual to satisfy specific needs."Special event adalah sebuah selebrasi yang dilaksanakan pada momen yang memiliki keunikan tertentu dengan bentuk seremonial dan ritual untuk memenuhi kebutuhan spesifik. 
Special event didefinisikan sebagai suatu kegiatan yang diselenggarakan untuk memperingati hal-hal penting sepanjang hidup manusia baik secara individual atau kelompok yang terikat secara adat, budaya, tradisi, dan agama yang diselenggarakan untuk tujuan tertentu serta melibatkan lingkungan masyarakat yang diselenggarakan pada waktu tertentu (Noor, 2013).

Menurut (Goldblatt, 2013) event management adalah kegiatan profesional mengumpulkan dan mempertemukan sekelompok orang untuk tujuan perayaan, pendidikan, pemasaran, dan reuni, serta bertanggung jawab mengadakan penelitian, membuat desain kegiatan, dan melakukan perencanaan dan melaksanakan koordinasi serta pengawasan untuk merealisasikan kehadiran sebuah kegiatan.

Terdapat lima tahap yang harus dilakukan untuk menghasilkan special event yang efektif dan efisien, yaitu penelitian, perencanaan, desain, koordinasi, dan evaluasi:

Penelitian yang dilakukan dengan baik akan mengurangi resiko kegagalan dalam pelaksanaan. Penelitian dilakukan untuk menentukan kebutuhan, keinginan, dan ekspektasi khalayak sasaran. Jadi, mereka diharapkan untuk hadir dalam ajang khusus. Penelitian yang dilakukan harus dilakukan dengan teliti dan komprehensif.
Terdapat tiga jenis riset yang digunakan dalam riset pre-event, diantaranya riset kuantitatif, riset kualitatif, dan kombinasi atau hybrid dari keduanya. Pemilihan metode riset yang cocok untuk setiap acara ditentukan oleh tujuan riset, waktu yang diberikan, dan dana yang tersedia.

Sebelum meluncurkan produk atau layanan baru, perusahaan akan melakukan riset pasar untuk menentukan kebutuhan, keinginan, hasrat, dan harapan dari target pasar.

Riset kuantitatif umumnya digunakan untuk menentukan informasi demografis seperi jenis kelamin, usia, pendapatan, dan fakta terkait lainnya tentang kondisi market di masa depan bagi sebuah acara.

Riset kualitatif digunakan untuk menelisik makna tersembunyi dalam riset kualitatif yang tidak dapat dimaknai dengan hasil yang berupa angka-angka. Riset kualitatif dapat berupa focus group, participant observation, atau case study. Metode yang tepat bergantung pada tujuan acara, waktu yang tersedia, dan pendanaan.

Seringkali perencanaan acara menggunakan kombinasi riset kuantitatif dan kualitatif untuk membuat keputusan mengenai kegiatan selanjutnya. Riset kuantitatif efektif mencakup unsur-unsur yang bisa diukur dengan angka untuk meningkatkan validitas pertanyaan. Perencanaan acara sebaiknya menggunakan focus group kecil atau tim ahli untuk meninjau 
pertanyaan sebelum melakukan survei. Para ahli dapat mengonfirmasi bahwa pertanyaan dapat dipahami dan valid untuk survei yang sedang dilakukan.

Sebelum merencanakan acara, biasanya diterapkan analisis SWOT untuk mendukung pengambilan keputusan. Analisis SWOT membantu peneliti dalam mengidentifikasi variabel internal dan eksternal yang dapat mencegah acara dari mencapai keberhasilan maksimal.

Strengths and Weakness dari suatu acara ialah elemen utama yang dapat dikenali sebelum acara berlangsung. Kekuatan dan kelemahan dapat ditemukan melalui focus group atau melalui wawancara dengan stakeholder penting. Jika kelemahan lebih banyak dari kekuatan dan tidak ada cara yang masuk akal untuk menghilangkan kelemahan dan meningkatkan kekuatan dalam perencanaan acara, perencana mungkin dapat menunda atau membatalkan.

Opportunity and Threats adalah dua faktor kunci yang muncul dalam pelaksanaan acara atau setelah acara selesai. Namun, selama proses riset, faktor-faktor ini harus dipertimbangkan dengan serius, karena berpotensi menimbulkan bencana bagi acara. Opportunity adalah aktivitas bisa memberikan manfaat bagi acara tanpa investasi besar oleh organisasi pelaksana acara. Threat adalah aktivitas yang menghambat dari optimalisasi pelaksanan acara. Threat yang paling nyata adalah cuaca, dalam hal ini faktor politik juga beresiko. Pemimpin politik lokal sebaiknya mendukung acara Anda untuk menjami kerjasama dengan semua instansi. Bentrokan politik dengan cepat dapat merusak perencanaan acara.

Dalam membuat keputusan untuk melanjutkan perencanaan acara, peneliti memiliki tujuan untuk mengidentifikasi opportunity daripada threat. Dengan menggunakan analisis SWOT, perencanaan acara tidak hanya dapat memindai lingkungan internal dan eksternal acara tetapi juga melanjutkan ke langkah berikutnya, yang melibatkan analisis weakness dan strength, dan memberikan solusi untuk meningkatkan proses perencanaan acara.

\section{METODE PENELITIAN}

Penelitian ini menggunakan pendekatan penelitian kualitatif, paradigma positivism dan metode deskriptif. Jenis studi deskriptif adalah suatu metode yang digunakan untuk menggambarkan atau menganalisis suatu hasil penelitian tetapi tidak digunakan untuk membuat kesimpulan yang lebih luas (Sugiyono, 2009). Penelitian deskriptif hanya memaparkan suatu situasi atau peristiwa.

Penelitian deksriptif memiliki tujuan sebagai penelitian yang dapat: (1) mengumpulkan informasi aktual secara 
rinci yang melukiskan gejala yang ada, (2) mengidentifikasikan masalah atau memeriksa kondisi dan praktek-praktek yang berlaku, (3) membuat perbandingan atau evaluasi, (4) menentukn apa yang dilakukan orang lain dalam menghadapi masalah yang sama dan belajar dari pengalaman mereka untuk menetapkan rencana dan keputusan pada waktu yang akan datang (Rakhmat, 2005).

Metode deskriptif kualititatif sangat berguna untuk melahirkan teori-teori tentative. Penelitian ini tidak mencari atau menjelaskan hubungan, tidak menguji hipotesis atau membuat prediksi. Metode deskriptif kualitatif mencari teori, bukan menguji teori: hypothesisgenerating bukan hypothesis testing, dan heuristic, bukan verifikasi. Ciri lain metode ini adalah menitikberatkan pada observasi dan suasana alamiah (natural setting) (Rakhmat, 2005).

Penelitian pada dasarnya ditujukan untuk mencari kebenaran atau untuk membenarkan suatu fakta. Usaha yang dilakukan oleh peneliti atau para prakisi dilakukan dengan menggunakan model-model tertentu, model tersebut biasanya dikenal sebagai paradigma (Moleong, 2012).

Penelitian ini menggunakan paradigma yang sama dengan penelitian yang dilakukan oleh Yuliyanti Sholihat, Susie Perbawasari dan Syauqy Lukman dalam peneleitiannya mengenai
"Proses corporate branding PJTV Bandung menjadi SKTV" (Sholihat, Perbawasari, \& Lukman, 2018). Dalam penelitiannya, menggunakan paradigma positivistik. Menurut Salim, keyakinan dasar aliran ini berakar pada paham ontology realism yang menyatakan bahwa realitas berada (exist) dalam kenyataan dan berjalan sesuai dengan hukum alam (natural laws) (Salim, 2006).

Penelitian mengenai manajemen special event dalam event Meet $U p$ "Positive Generation" ini juga menggunakan paradigma positivistik, sebab penelitian menggunakan pola pikir deduktif. Penelitian ini menggunakan kerangka deduktif, dimulai dari penggunaan konsep manajamen special event yang diturunkan menjadi pertanyaan penelitian, kemudian harus dijawab melalui penelitian yang dilakukan dengan menanyakan langsung kepada objek yang diteliti. Objek dapat memberikan jawaban langsung kepada peneliti, jawaban tersebut akan menjadi hasil dari tujuan penelitian yang telah disusun berdasarkan konsep manajemen sehingga mendapatkan kesimpulan. Pada penelitian ini menggunakan teknik pengumpulan data yang selanjutnya dapat digunakan peneliti untuk mengumpulkan data di lapangan serta dipaparkan ke dalam hasil penelitian dengan menggunakan tiga teknik pengumpulan data, yaitu observasi, wawancara, dan dokumentasi (Fajrin, N., Bakti, 
I dan Novianti, E., 2018).

\section{HASIL DAN PEMBAHASAN}

Event merupakan salah satu tools of public relations sebagai upaya memulihkan ataupun mempertahankan citra suatu perusahaan, organisasi, lembaga, maupun institusi. Dalam proses manajemen special event, tahapan pertama yang dilaksanakan adalah riset. Riset berguna untuk menentukan hal apa yang ingin dicapai dan bagaimana cara untuk mencapainya. Penelitian atau riset yang dilakukan dengan baik akan mengurangi resiko kegagalan dalam pelaksanaan.

Riset menurut (Pudjiastuti, 2010) bahwa riset awal untuk menganalisis situasi sangat perlu dilakukan agar dapat diperoleh data dan fakta yang aktual sebagai bahan pembuatan perencanaan special event. Pengumpulan data dapat dilakukan melalui survei, wawancara, FGD (focus group discussion), kliping, analisis media, atau melalui data sekunder, baik secara formal maupun informal (Tobing, Perbawasari, \& Erdinaya, 2017).

Sedangkan riset menurut (Cutlip, Center, \& Broom, 2005) digunakan untuk mengidentifikasi tujuan utamanya sebagai upaya mengurangi kebutuhan, keinginan, dan ekspektasi para peserta. Peneliti melakukan partisipan langsung untuk mewujudkan keinginan mengungkap fenomena yang luput dari perhatian. Peneliti melakukan pengamatan sekaligus berpartisipasi di dalamnya dengan harapan mendapatkan data yang lebih banyak, lebih dalam, dan lebih terperinci.

Faktor utama diselenggarakannya Meet Up "Positive Generation" melihat dari besarnya populasi generasi milenial (Y) saat ini berpengaruh pada perubahan pola konsumsi media secara umum. Arus informasi tidak lagi satu arah dan linear. Karakteristik media baru (new media) memungkinkan potensi pengaruh yang positif dan negatif sekaligus terhadap generasi muda. CNN Indonesia berharap dapat berkontribusi positif dalam memberikan acuan bagi para generasi milenial mendapatkan manfaat positif dari perkembangan teknologi dan media baru ini.

EventMeet Up"Positive Generation" dalam hal ini berkolaborasi dengan BkkbN. Hal inilah yang membuat tema dari event ini yaitu positive generation. Kolaborasi CNN Indonesia-BkkbN GENRE diharapkan mampu menginspirasi para mahasiswa melalui rangkaian kegiatan yang berkualitas, menarik, dan relevan dengan kebutuhan mereka.

"Nah kalau yang untuk BkkbN ini kan, kita ngikut konsep yang dari BkkbN, mereka pengennya seperti apa, kan BkkbN kan punya campaign yaitu GenRe atau Generasi Berencana. Otomatis harus ngikutin campaign-nya mereka kan, makanya kita masang temanya positive generation. Jadi event ini mengemas atau bertujuan untuk membuat yang hadir itu terinspirasi menjadi generasi positif itu. 
Dengan kita menghadirkan anak-anak muda yang bisa menjadi contoh, mereka yang sudah menjadi positive generation," (Ferdiansyah, 2019).

Hal tersebutlah yang mendasari diselenggarakannya event Meet Up "Positive Generation". Selain itu event Meet Up "Positive Generation" memiliki beberapa tujuan yaitu untuk menghasilkan revenue bagi perusahaan, meningkatkan juga mempromosikan $\mathrm{CNN}$ Indonesia terhadap khalayak, serta untuk memberikan edukasi kepada generasi muda terkait materi yang sedang menarik dikalangan remaja, agar mereka sudah bisa menentukan akan melakukan apa untuk menjadi Generasi yang berkualitas untuk bangsa.

Hasil data riset yang dilakukan $\mathrm{CNN}$ Indonesia diperoleh berdasarkan data lapangan yang didapat melalui observasi langsung saat event berlangsung, maupun wawancara mendalam dengan pihak-pihak yang terlibat langsung dalam proses riset event Meet $U p$ "Positive Generation" yang diselenggarakan oleh CNN Indonesia. Sebagai penyelenggara Meet Up "Positive Generation", CNN Indonesia melakukan riset terlebih dahulu untuk mengetahui kebutuhan dan keinginan target sasaran. Menurut hasil wawancara dengan Dicky Ferdiansyah selaku Project Manager Meet Up "Positive Generation":

"Yang pertama itu riset tempatnya, kampusnya grade nya harus A atau B. Yang penting kampusnya harus baguslah, nah dari situ kan kita meeting sama anak kampusnya, sama dekan-dekannya, dari situ kita menentukan penontonnya bakal siapa aja, program jurusannya harus apa aja. Sebenarnya risetnya lebih ke sharing dengan mereka sih, sharing dengan orang kampusnya langsung, seperti apa event itu. Jadi yang pertama cari dulu tempatnya, trus kita datengin ke tempatnya baru kita sharing siapa yang nanti bakal jadi panitianya, tujuan acaranya kemana. Gak lama sih risetnya, cuma sekali ketemua aja gitu," (Ferdiansyah, 2019).

Jadi langkah awal riset yang dilakukan pihak CNN Indonesia yang dilakukan oleh project manager event Meet Up "Positive Generation" ini yaitu menentukan tempat diadakannya event yaitu di kampus-kampus pilihan yang sudah di seleksi sebelumnya. Penentuan tempat diselenggarakannya event juga tidak terlalu lama, setelah sudah ditentukan kampus-kampus mana saja yang terpilih, maka langkah selanjutnya yaitu melakukan audiensi kepada pihak kampus untuk menjelaskan maksud dantujuan dari diadakannya event Meet Up "Positive Generation" tersebut.

Setelah dilakukan penentuan tempat diselenggarakannya event Meet $U p$ "Positive Generation", riset selanjutnya yaitu menentukan konten apa saja yang disajikan dalam event tersebut. Hal tersebut dijelaskan langsung oleh Mas Dicky selaku project manager event Meet Up "Positive Generation", bahwa:

"Untuk proses riset yang dilakukan itu ngeliat dulu dari tema acaranya kayak gimna, kalau Meet $U p$ yang kemarin kan positive generation, jadi harus cari pembicara-pembicara yang positif. Maksudnya masih muda tapi sudah 
melakukkan hal yang positif. Biar bisa menjadi representative buat anak-anak kampusnya. Nah sebenernya kalau misalnya sudah masuk ke kriteria yang kita inginkan, yang masih muda terus omzet nya sudah gede untuk yang enterpreuner, yaudah kita langsung kontak dan jadi pembicara gitu," (Ferdiansyah, 2019).

Riset sangat perlu dilakukan agar dapat memperoleh data dan fakta yang aktual sebagai paham perencanaan special event. Hal ini sesuai dengan pernyataan bahwa riset perlu dilakukan untuk mengidentifikasi karakteristik khalayak sasaran (Tyas, Hafiar, \& Sani, 2017). Bentuk riset yang dilakukan penyelanggara Meet $U p$ "Positive Generation" adalah menentukan pembicara-pembicara yang akan mengisi event Meet Up "Positive Generation" berdasarkan online riset melalui akun Instagram ataupun You Tube.

"Nah kemarin itu karena event nya dadakan, jadi kita hanya pake analisis yang feeling aja. Ngeliat dari kalau misalnya dari entrepreuner, kita liat produknya apa, kita analisis produknya punya followers-nya berapa. Kalau banyak berarti oh bagus, terus dari personal nya juga, oh followersnya banyak terus YouTube nya juga bagus. Oh kalau gitu go ahead. Yaudah berarti lanjutin dia jadi pembicara, tapi ketika ada referensi entrepreneur dari klien, followersnya kurang terus dampaknya kurang ke masyarakat, ya kita gak terima, kita gak panggil gitu. Yang kita panggil adalah yang sudah kita analisis berdasarkan sosial media. Karenakan hanya sosial media saja yang bisa kita lihat, kita gabisa nanya-nanya langsung ke orangnya untuk nge analisis kehidupannya kan. Jadi lewat sosial media atau google saja," (Ferdiansyah, 2019).

Goldblatt berpendapat bahwa terdapat tiga jenis riset yang dapat dilakukan dalam pre-event yakni riset kuantitatif, kualitatif, dan kombinasi atau hibrid dari keduanya (Goldblatt, 2013). CNN Indonesia Meet Up "Positive Generation"menggunakan riset kualitatif dalam acara ini dengan melakukan diskusi bersama kepala departemen marketing public relations, tim sales, ataupun pihak sponsor dalam acara ini.

Data yang dibutuhkan dalam riset kuantitatif seperti jenis kelamin, usia, dan demografis lainnya telah ditetapkan bersama dengan pihak sponsor yaitu BkkbN. Fokus peserta dalam event Meet Up "Positive Generation" ini adalah generasi milenials. Dalam tahap riset menurut Goldblatt perlu melakukan namun menurut Frederick F. Jebada selaku Head of Marketing Public Relations Departement bahwa (Goldblatt, 2013):

"Menggunakan SWOT analysis merupakan cara lama yang tidak kekinian, sehingga kita sudah tidak menggunakan SWOT analysis lagi," (Jebada, 2019).

Setelah semua data yang dibutuhkan penyelengara sudah terpenuhi dan sesuai dengan keinginan pihak terkait, maka penyelenggara siap melakukan ke tahap selanjutnya.

Menurut Cutlip, definisi Public Relations yakni: Public Relations is the management function which evaluate public attitudes, identifies the policies and prochedures of an individual or an organization with the public 
interest, and plans an executes a program of action to earn public understanding an acceptances (Ardianto, 2011). Public Relations adalah fungsi manajemen yang menilai sikapsikap publik, mengidentifikasi kebijakankebijakan dan prosedur-prosedur dari individu atau organisasi atas dasar kepentingan publik dan melaksanakan rencana kerja untuk memperoleh pengertian dan pengakuan publik (Cutlip, Center, \& Broom, 2005).

Mendefinisikan Masalah atau Peluang (Defining Public Relations Problem). Tahap pertama meliputi memperhatikan dan mengawasi pengetahuan, opini, sikap, dan tingkah laku pihak-pihak yang berhubungan dan terpengaruh akan aksi dan kebijakan dari suatu organisasi. Ini merupakan fungsi intelegensi dan organisasi. Tahap ini merupakan fondasi dari langkah-langkah berikutnya dalam proses penyelesaian masalah dengan menentukan “Apa yang terjadi sekarang?" (Cutlip, Center, \& Broom, 2005).

Public Relations merupakan fungsi manajemen dalam organisasi, maka aktivitas Public Relations sangat berkaitan dengan aktivitas organisasi, sehingga riset-riset Public Relations merupakan bagian dari riset organisasi. Hal ini serupa dengan hasil penelitian yang menyebutkan bahwa riset public relations pada dasarnya berkaitan dengan upaya mengukur bagaimana opini publik (internal atau eksternal) terhadap perusahaan (Pakaradena, Hafiar, \& Nugraha, 2018). Selain itu, untuk meningkatkan awareness masyarakat agar menyentuh sense dan feel pengunjung, dapat dipertimbangkan unsur gerak (Motion), warna (Colour), suara (Sound), dan cahaya (Light). Unsur-unsur ini dapat diterapkan pada dekorasi, lighting, penyusunan layout venue, rundown, penyusunan materi cue card dan pemilihan $\mathrm{MC}$ (Pakaradena, Hafiar, \& Nugraha, 2018).

Defining the problem yang dilakukan CNN Indonesia ini merupakan tujuan dari Departemen Marketing Public Relations CNN Indonesia dalam membuat event off air $\mathrm{CNN}$ Indonesia Meet Up "Positive Generation". Dimana tujuannya adalah meningkatkan awareness generasi milenials mengenai $\mathrm{CNN}$ Indonesia dan mengedukasi mereka untuk menjadi generasi yang positif dan berencana dengan melakukan kolaborasi dengan BkkbN GenRe. Oleh karena itu, dalam proses riset yang dilakukan CNN Indonesia juga diperhatikan bagaimana cara memberikan kesan tersendiri kepada publik sehingga dapat memberikan kesan setelah menghadiri event Meet $U p$ "Positive Generation" yang diselenggarakan oleh CNN Indonesia.

\section{SIMPULAN}

Riset yang dilakukan oleh CNN Indonesa sebelum menyelenggarakan event Meet Up 
"Positive Generation", antara lain riset kualitatif dan online riset yang ditilengkapi dengan hasil evaluasi dari event Meet Up yang sebelumnya pernah diadakan oleh CNN Indonesia.

Pada sebuah penyelenggaraan kegiatan, diperlukan riset terlebih dahulu. Seperti halnya yang dilakukan oleh CNN Indonesa sebelum menyelenggarakan event Meet $U p$ "Positive Generation". Riset dilakukan untuk mengetahui situasi dan kondisi generasi milenial terkait melihat besarnya populasi generasi milenial (Y) saat ini, yang berpengaruh pada perubahan pola konsumsi media secara umum. Arus informasi yang sudah tidak lagi satu arah dan linear juga karakteristik media baru (new media), memungkinkan memiliki potensi pengaruh yang positif dan negatif sekaligus terhadap generasi muda.

Oleh karena itu, sebaiknya penyelenggara melakukan riset secara komprehensif dengan cara menyebarkan angket atau kuesioner tentang pola konsumsi media para generasi milenials atau melakukan observasi langsung sebelum pelaksanaan event sehingga perencanaan dapat lebih sesuai dan lebih mudah untuk mencapai tujuan yang telah ditentukan sebelumnya.

\section{DAFTAR PUSTAKA}

Alatas, A. (2019, March 15). Wawancara PraSurvei. (A. P. Yurita, Interviewer) Jakarta. Ardianto, E. (2011). Metode penelitian untuk public relations. Bandung: Simbiosa Rekatama Media.

Cutlip, S., Center, A., \& Broom, G. (2005). Effective public relations. New Jersey: Prentice Hall.

Fajrin, N., Bakti, I dan Novianti, E. (2018).

City Branding Sawahlunto Kota Wisata Tambang yang Berbudaya Melalui Event Sawahluto International Songket Carnival (Sisca) 2016. PRofesi Humas, 2(2), 169185.

Farah. (2019, Maret 15). Wawancara PraSurvei. (A. P. Yurita, Interviewer) Jakarta.

Ferdiansyah, D. (2019, February 15).

Wawancara Pra-Survei. (A. P. Yurita, Interviewer) Jakarta.

Goldblatt, J. (2013). Special event: creating and sustaining a new world for celebration. Canada: John WIley \& Sons Inc.

Jebada, F. (2019, February 15). Wawancara PraSurvey. (A. P. Yurita, Interviewer) Jakarta. Moleong, M. P. (2012). Metodologi penelitian kualitatif. In M. Prof. Dr. Lexy J. Moleong, Metodologi Penelitian Kualitatif (p. 5). Bandung: PT Remaja Rosdakarya.

Noor, A. (2013). Manajemen event. Bandung: Alfabeta.

Pakaradena, A., Hafiar, H., \& Nugraha, A. R. (2018). Proses Public Relations dalam Program Layar Tancap Untuk Semua oleh SCTV. ProTVF: Jurnal Kajian Televisi dan Film, 2(2), 127-143.

Pudjiastuti, W. (2010). Special event: alternatif jitu membidik pasar. Jakarta: Gramedia.

Rakhmat, J. (2005). Metode penelitian komunikasi. Bandung: Remaja Rosdakarya. Salim, A. (2006). Teori dan paradigma: penelitian sosial. Yogyakarta: Tiara Wacana.

Sholihat, Y., Perbawasari, S., \& Lukman, S. (2018). Proses corporate rebranding pjtv 
Bandung menjadi sktv. ProTVF: Jurnal Kajian Televisi dan Film, 2(2), 173-190.

Sugiyono. (2009). Memahami penelitian kualitatif. Bandung: Alfabeta.

Tobing, C. M., Perbawasari, S., \& Erdinaya,
L. K. (2017). Manajemen special event ajb bumiputera 1912 Bandung melalui customer gathering. PRofesi Humas, 2(1), 13-22. 